A REPORT ON THE PHYSIOLOGICAL ACTION OF CHLOROFORM, CRITICISM OF THE SECOND HYDERABAD

\section{CHLOROFORM COMMISSION.}

BY W. H. GASKELL, M.D., F.R.S., Lecturer on Physiology in the University of Cambridge, AND

L. E. SHORE, M.D.,

Demonstrator in Physiology in the University of Cambridge.

$$
\text { (Continued from page 111.) }
$$

Comparison of Chloroform Injection and Chloroform INHALATION.

THEse experıments point directly to the conclusion that chloroform causes a fall of blood pressure by the weakening of the heart's contractions and not by a paralysis of the vasomotor centre; when, however, we attempt to explain the effects of chloroform inhalation by the experience thus gained we must always remember that liquid chloroform possesses a much more powerful irritant action upon the tissues than the vapour of chloroform. This is naturally only a question of degree, for the stimulating action of strong chloroform vapour is shown most markedly by the reflex effects produced upon the nasal ard pharyngeal membranes. Although, then, we should expect for this reascn that injection of chloroform into the vascular system should produce stronger signs of irritant action than its inhalation, set there can be no doubt that these experiments show that such injections of chloroform, whether brainwards or heartwards, do produce also anæsthesia and paralysis of respiration resembling in effect the symptoms seen upon inhalation of the drug. We are therefore, it seems to us, justified in concluding that although these experiments are not of themselves absolute proof of the action of chloroform when inhaled, yet they support rather than oppose the view that chloroform when inhaled differs in its action from chloroform when injected in degree rather than in kind, and afford therefore valuable evidence of the action of chloroform if they prove to be in accordance with the evidence given by other experiments in which chloroform was brought into the blood by direct inhalation. Another possibility must be borne in mind when discussing the value of these experiments, namely, the possibility that fluid chloroform when injected into an artery may cut off the blood supply from one or more vascular areas supplied by that artery, either because the fluid itself obstructs some of the small arterioles owing to its cohesive power and immiscibility, or because its irritant action causes capillary stasis, and so blocks the flow through the area in question. In either case the effect produced in any experiment would depend upon the position of the small vessels which were blocked rather than upon the specific action of the drug.

Undoubtedly the effects produced by chloroform when injected into the cerebral arteries resemble in many respects those produced by a blocking or ligature of those arteries. Thus the characteristic lengthening of each contraction of the diaphragm when chloroform is injected into the carotis recalls forcibly to mind the respiratory spasms described by Marckwald when the higher brain paths connected with respiration as well as the vagi nerves were cut, and Marckwald ${ }^{6}$ has shown that the same kind of elongated spasmodis respiration can be obtained by the injection of wax into the carotis so as to block the arteries supplying the posterior corpora quadrigemina, if at the same time the vagi nerves are cut. Further, Marckwald has shown that such elongated respiratory spasms can be cut short so that the type of respiration more nearly resembles the normal by the stimulation of such inhibitory nerves as the superior laryngeal or trigeminal. Our experiments have shown us that the lengthened diaphragm contractions produced by injection of chloroform into the carotis can also be cut short with a consequent quickening of the rate of respiration when a stimulating vapour, such as ammonia or chloroform, is applied to the nose.

In Marckwald's wax injection experiments the spasmodic type of respiration was caused by the complete removal of the regulating influence of the lungs on the respiration in combination with a partial removal of the regulation from the higher brain regions. In our experiments, when the vagi nerves were intact, it was easy to show that their regulating influence was not impaired to any very great extent, for every inflation or suction was still able to produce the well-known Hering-Breuer effects described by Head, $^{7}$ so that if the prolonged respiratory spasms caused by wax injection and ours caused by chloroform injection have any common ground of origin, that common cause must be sought. for in the paralysis of higher brain paths combined with a. possible diminution of the regulating power of the vagi nerves.

Comparison of Chloroform Injection and Ligature of Brain Arterims.

Again, it is interesting to compare the effect of ligature of the four brain arteries with the effect of injection of chloroform into them. We have made a number of experiments. for the purpose of observing the sequence of events which follows ligature of the four brain arteries. In most cases the two subclavian arteries were tied proximal to the vertebrals, as well as the vertebrals and carotids. In order to estimate the extent of the circulation in the brain after ligature of these vessels, we placed a cannula in the peripheral end of the carotis as well as the ordinary blood-pressure cannula in the end connected with the heart, and tied the external carotis and auricular arteries as well as the superior thyroid. In this way the only communication with the cannula is by way of the internal carotis. and the blood pressure measured is that in the circle of Willis. This method was used by Hürthle. ${ }^{8}$ It gives a rough-and-ready test of the amount of diminution of the blood in the circle of Willis, and also of the efficacy of the ligatures round the vertebrals and carotids. With the ligature of each vessel the circle of Willis pressurefalls, while the ordinary blood pressure rises, and, finally, when all four vessels are ligatured, the pressure in the circle of Willis is very low, and then falls very slowly, nearly to. zero-that is to 3 to $5 \mathrm{~mm}$. $\mathrm{Hg}$, while at the same time the ordinary pressure is very high. Further, it is clear that such a proceeding as stoppage of the heart by vagus stimulation. must produce a fall in both blood-pressure curves as long as the brain arteries are open, while naturally it would produce a fall in only the systemic blood-pressure curve if the closure of the four brain arteries has been efficiently performed. This control we found to be quite satisfactory; as long as onevessel was unclamped or unligatured then both blood pressures responded to the peripheral end of the vagus nerve. When they were all clamped no sign of a fall was to be seen in the circle of Willis pressure curve, although naturally the fall in the systemic blood-pressure curve was as great as ever.

Further, the efficiency of the ligatures was seen by opening the atlo-occipital membrane after death, when it was found that no cerebro-spinal fluid ran out, and that the fourth ventricle looked white and bloodless. As a rule the last artery to be closed was the carotis on the left side, the two ends of the carotis on the right side having been previously fixed in connection with the two mercury manometers. A respiratory tracing was not taken, but the condition of the respiration was noted occasionally. It was found, as is well known, that the ligature or clamping of the last artery caused considerable struggling, the well known Kussmaul-Tenner convulsions, and violent respirations; if, however, the clamp was immediately taken off these ceased very quickly. By putting on and taking off the clamp at frequent intervals, taking it off whenever the animal commenced to struggle, we were enabled finally to leave the clamp permanently on without any struggling, and we always found that complete closure in this way was followed by a very marked rise of 
blood pressure in the cannula connected with the heart, and an equally marked fall of pressure in the cannula connected with the circle of Willis ; stimulation of the peripheral end of the vagus then produced no effect on this latter pressure. In no case have we seen any attempt at a spontaneous recovery of blood pressure in the circle of Willis, much less an increase of that pressure above its original height, as mentioned by Corin, ${ }^{9}$ provided that the subclavians were ligatured proximal to the vertebrals ; in fact, our experiments agree closely with Hürthle's, and we conclude, as he does, ${ }^{10}$ that there is no evidence of the establishment of any efficient collateral circulation after the ligature of the four brain arteries. It is, however difficult to believe that no blood whatever reaches the medulla oblongata, seeing that, as will be explained later, chloroform still appears able to produce an effect upon respiration. The effect of this cutting off of the circulation to the brain is in all cases death by failure of respiration, and it is remarkable how long a time the animal is able to continue to breathe with the blood supply to the medulla oblongata cut off. In our experiments respiration has continued for a length of time, varying between eight minutes to thirty minutes after the closure of the last blood vessel. In all cases the rate of respiration becomes slower and slower, so that the stoppage is a gradual one. Throughout the whole time during which the respiration lasts the aortic blood pressure, which had become very high, immediately after the ligature of the last artery remains high, the amount of fall being very slight, and the height at the time of cessation of respiration is greatly above the normal blood pressure as seen before the brain arteries were ligatured. The blood pressure does not fall to any extent until after the respiration has ceased. This long continued high blood pressure is further characterised by the presence of regular periodic undulations, which are in many cases remarkably regular, and resemble those seen when chloroform is injected into the vertebral artery. Finally, the ligature of the brain arteries produces a complete anæsthesia, as shown by the absence of any corneal or conjunctival reflex before the respiration ceases, so that in this case, as in the case of injection of chloroform into the brain arteries, paralysis of the higher centres occurs first, then paralysis of the respiratory centre, and finally paralysis of the vasomotor centre. Primary excitation of the cardio-inhibitory centre, as evidenced by a slowing of heart rate soon after the complete closure of the brain vessels, is clearly indicated on some of the curves. We see then that an insufficient supply of blood to the medulla oblongata causes an excitation, followed by paralysis, of the various centres 'situated there, and that, just as in the case of chloroform injection, the excitation of the vasomotor centre lasts so much longer than that of the respiratory centre as to keep the blood pressure high during the time the respiration is failing, and even up to the time of its stoppage. In both cases the vasomotor centre is ultimately paralysed for it is impossible in either instance by means of artificial respiration to prevent the blood pressure from falling after the cessation of natural respiration.

Comparison of Action of Chloroform and of Other Agents ON THE MEDTLLARY CRNTRES

The resemblance in the sequence of events connected with the respiratory and vasomotor centres when the brain arteries are ligatured, and when chloroform is injected into those arteries, emphasises one most important conclusion, namely, that it is not necessary or even probable that a paralysing agent should paralyse these two neighbouring centres simultaneously, the evidence is rather in the direction that the excitation of the vasomotor centre will outlast both the excitation and subsequent paralysis of the respiratory centre whenever an agent which first excites and then paralyses is applied to the medulla oblongata.

This conclusion is in complete accord with other evidence, such as the action of amyl nitrite when injected into the carotis, and the effect of pressureapplied to the fourth ventricle. Cash and Dunstan, ${ }^{11}$ in a recent paper, have shown that the injection of amyl nitrite into the brain arteries produces a marked rise of blood pressure which lasts even after the re-

$$
9 \text { Quoted by Hürthle. }
$$

11 Proceed. Roy. Soc., vol. xlix, p. 314 spiration shows signs of failure. So also Horsley and Spencer, ${ }^{12}$ in their paper "On the Changes produced in the Circulation and Respiration by Increase of Intracranial Pressure," show that if the vagi nerves are cut so as to abolish the action on the heart an increase of intracranial pressure causes a marked rise of blood pressure with a failure of respiration; indeed the respiratory and vasomotor centres are so related to each other that, when the respiration has ceased owing to a moderate increase in the intracranial pressure, then a further increase of that pressure causes a still greater rise of blood pressure with the result of restarting the respirations. The paralysis of the vasomotor centre, in consequence of longcontinued increase of intracranial pressure, only occurs long after natural respiration has been abolished, and artificial respiration has been employed for some time. In fact, so far from the same influence producing simulianeously similar effects upon the two neighbouring centres of respiration and vasomotor action, we see rather that the vasomotor centre is. subordinate to the much more important respiratory centre, Nature's safeguard action being to keep up the blood pressure as long and as high as possible for the purpose of recovering the failing respiratory centre by supplying it with a large supply of blood. A larger supply of blood is brought to the brain region with the rise of blood pressure, because the evidence of physiology in recent years points to the conclusion that the vessels of the abdominal area and of the brain are not simultaneously constricted when the vasomotor centre is. stimulated, but rather that the brain vessels behave like the vessels of the skin, and are dilated when the vessels of the abdominal area are constricted.

These experiments upon the effect of injection of chloroform into the brain arteries on the one hand, and into the jugular vein on the other, point strongly to the conclusion that the fall of blood pressure observed when chloroform is inhaled is due to a weakening of the heart's action, and not to a primary paralysis of the vasomotor centre; still, however, as already mentioned, they cannot be regarded as a conclusive proof that such is the action of chloroform when inhaled. We require, therefore, as a supplement to these experiments, some method by which chloroform can be inhaled in the usual manner, and the blood containing chloroform. thus inhaled can be sent either to the heart alone or the brain alone at will. As already mentioned, we have devised the method of cross circulation between two animals in order to test this point.

Cross Crrculation Experiments.

1. Method of Performing the Experiment and the Effects of Establishing the Cross Circulation.-In order that chloroform, when inhaled in the ordinary way, could be carried to the brain only or to the heart only, the circulation through the brain was separated from the general circulation, and a. supply of blood for the brain obtained from another animal. The exact way in which this was accomplished varied in different experiments, for one reason because the relative sizes of the animals selected determined to some extent the number of vessels which it was considered necessary to connect from one animal to another to obtain an adequate cross circulation.

In general, the plan adopted was to connect the cerebral ends of one or both carotids of the animal, whose cerebral and general circulatory systems were to be separated-and this animal we will speak of as the fed-to the cardiac ends of one or both carotids of the other animal, which we will call the feeder. When the remaining brain arteries of the fed animal were ligatured, the brain was supplied by blood reaching it by the internal carotids, and derived directly from the common carotids of the feeder. One external jugular vein of the fed animal was similarly cross connected to the cardiac end of one external jugular of the feeder, and the other external and the two internal jugulars of the fed animal were ligatured, so that the blood from the brain was very largely conducted back to the feeder, and was not allowed to reach the general circulation of the fed. In an experiment where a large bulldog of 17 kilogrammes supplied the brain of a small terrier of 5 kilogrammes, one carotid of the large dog was connected by a Y-piece to both carotids of the small dog, and 
the brain of the latter was wholly supplied by this one carotid.

The larger animal was, when possible, always selected for the feeder; but when rabbits were used, as there was no considerable difference in size of the animals, it was considered necessary to connect as many cross channels as possible from one rabbit to the other, so that an adequate supply of blood might be secured. In one such experiment both carotids and one subclavian of the feeder were connected severally to the two carotids and one subclavian of the fed, all the branches of the latter vessel, except the vertebral and the vessel itself on the cardiac side of the vertebral, being ligatured. In this case, therefore, blood was derived from the feeder by three channels, namely, the two carotids and one vertebral. The other vertebral of the fed animal was ligatured, and a return of blood was secured by one pair of cross connected jugular veins, the other external jugular vein of the fed animal being ligatured. In most cases the external carotids of the fed animal were ligatured, so that the internal carotids received all the blood derived by cross connection with the common carotids of the feeder.

In all cases an adequate supply of blood was left to the brain of the feeder, for in no case were its vertebral arteries interfered with, and in some experiments one carotid was left as well. The blood pressure in the general circulatory system of both animals was registered from the femoral arteries. In order to reduce the tendency to the clotting of the blood the connecting cannulæ were made as short as possible by dissecting out a considerable length of the vessels and by bringing their ends very close together. It was found convenient to suture together the reflected skin of the neck of one animal to that of the other, and so to form a bed on which the connected vessels could rest. It was, however, found necessary to diminish the clotting power of the blood by an injection of extract of leech or of peptone. The amount of these substances used was small, so that the blood pressure should be depressed as little as possible. Moreover, the injection was made some considerable time before the cross circulation was established; the immediate effect of the injection upon the blood pressure had then to some extent passed off. It will, however, be noticed, on reference to the protocols or the tracings, that the blood pressures, especially of the feeders, are small.

In the experiment made on February 18th (Fig. 6), referred to above, the feeder, a dog of 17 kilos., received an injection of $7 \mathrm{grm}$. of peptone ( 0.4 per kilo), and two hours later, immediately before the cross circulation was established, the blood pressure in the femoral artery was $68 \mathrm{~mm}$. (Fig. 6, Tracing $a$ ). This is decidedly low for so large an animal, so that in this case the depression caused by the injection of peptone had not been fully recovered from. In the fed animal, in the same experiment the femoral blood pressure immediately before the cross circulation was established, which was two hours and a-half after the injection of $2 \frac{1}{4}$ grm. of peptone, was $122 \mathrm{~mm}$. (Fig. 6, Tracing a). The much higher blood pressure in this case is not due to recovery from the depression, caused by the injection being more complete in this animal than in the large one, but to the fact that at this moment many arteries in the neck of the small dog are occluded. The ascending cervical artery on the right side was ligatured, and the two carotids, which had been connected to the left carotid of the feeder, were still clamped. The left vertebral and the left subclavian were also tied, the ligature of the latter vessel, which was even placed proximal to the origin of the vertebral, being to prevent any possibility of blood passing by the ascending cervical arteries from reaching, by anastomoses, the upper part of the vertebral. Thus the right vertebral was the only vessel left for the supply of blood to the brain. Such an extensive closure of vessels accounts at once for the higher blood pressure in the fed animal as compared with the feeder. The right vertebral was tied as nearly as possible at the same moment as the clamps were removed from the carotids and the jugular veins (the right external jugular of the fed being connected with the left of the feeder), and the cross circulation in this way established, so that at no time was the brain of the fed deprived of a supply of blood.

We are assured of this, because in no case in our experiments has there been at this moment any struggling or marked change in the respiration of either animal, except in one case, where the last brain artery was by mistake tied before the clamps on the connected vessels were removed, as will be mentioned later in the description of the experiment on February 20th. When the cross circulation was established, the blood pressure in the fed animal rose still higher. In one minute and a-half it had risen to $160 \mathrm{~mm}$., and this was the maximum it attained, while that in the feeder had fallen slightly to $58 \mathrm{~mm}$. (Fig. $6 \mathrm{~b}$ ). The rise of pressure in the fed animal shows that there is a supply of blood from the feeder, and probably that the complete return of blood from the brain of the fed back to the feeder is not secured. In this particular experiment, where the right external jugular of the fed was connected to the left external jugular of the feeder. only the left external jugular of the fed was ligatured, so that there still remained the two internal jugulars, by which some portion of the blood would no doubt pass into the general circulation of the fed animal. The slight fall of pressure in the feeder probably also indicated that there was some bleeding of one animal into the other going on, but this fall would undoubtedly have been much greater if a large proportion of the blood had not been returned by the cross-connected jugulars.

This fall of pressure in the feeder does not always occur. In another experiment the left carotis of a dog of 12 kilos. was connected to the right carotis only of the fed animal, a dog of 5 kilos. Both vertebrals of the fed were ligatured and the last brain artery, the left carotis, was clamped at the moment the cross circulation was established. The right jugular of the fed was in connection with the left jugular of the feeder, and the left external jugular of the fed was ligatured. In this case, also, peptone had been injected. The small dog had received 2.5 grm. feptone ( 0.5 per kilo) one hour and a-half, and the large dog 4.5 grm. peptone ( 0.3 per kilo) half an hour before the cross circulation was established. Just before this was done, the femoral pressure of the feeder was $65 \mathrm{~mm}$., the low pressure being due to the peptone having been injected only half an hour previously. The femoral pressure of the fed at the same time was $132 \mathrm{~mm}$. When the cross circulation was established, this slowly rose, and in one minute was 164 $\mathrm{mm}$., and that of the feeder did not in this case fall, but, on the contrary, rose slightly to $70 \mathrm{~mm}$.

In the experiments with rabbits, where the cross supply of blood was derived by three channels, there is a more marked loss of blood by the feeder.

In the experiment on February 23rd (Fig. 9), one hour and a.half after the injection of leech extract, the femoral pressure of the fed animal was $70 \mathrm{~mm}$. At this time the left vertebral was the only artery supplying the brain. The subclavian on the right side had been ligatured on the cardiac side of the vertebral, and all the other branches of the subclavian tied, so that the vertebral could by means of the distal portion of the subclavian be connected with the left subclavian of the feeder; and the two carotids were at this moment also clamped and connected to the two carotids of the other animal. The pressure in the feeder at this moment was $84 \mathrm{~mm}$. (Fig. 9, Tracing $a$ ). The two carotids and the left subclavian of this animal were then clamped. The return of blood was secured by the connection of the right jugular of the fed with the left of the feeder, the other external jugular of the fed being ligatured.

When the cross circulation was established, and the last brain artery of the fed tied, the pressure in this animal rose, and in one minute and a-half was $94 \mathrm{~mm}$., while that of the feeder fell to $44 \mathrm{~mm}$. (Fig. 9, Tracing $b$ ). This considerable fall of pressure of the feeder may be partly accounted for by hæmorrhage into the fed, which must undoubtedly take place at first into the relatively empty vessels of the brain of that animal, but that this does not continue to any extent is probably shown by the fact that the pressure did not continue to fall, but, on the contrary, rose slightly, and three minutes after the circulation was established was $53 \mathrm{~mm}$. Again, the mere effect of closure of both carotids and of one subclavian is to drive the blood pressure abnormally high, and, if this is due to mechanical causes and not to increased activity of the vasomotor centre consequent on the diminished supply of blood to the brain, the pressure in the feeder would fall when these vessels are again opened.

The rise of blood pressure in the fed animal reaches its 
maximum rather quickly, and then remains fairly constant, as is seen clearly in the experiments with dogs. This rise cannot be looked upon as due to an escape of blood from its brain into its general circulation. Such escape would need to be very large to produce the considerable rise observed, if, indeed, it could produce the effect at all. The explanation is rather one in accordance with the observations of Horsley and Spencer, who found that an increase of intracranial pressure led to a rise of blood pressure by increased activity of the vasomotor centre.

Eight cross-circulation experiments were made, three with two dogs, three with two rabbits, and two where the attempt was made to supply the brain of a rabbit with blood from a dug. This last procedure was unsuccessful, as the rabbit in both cases died very soon after the cross circulation was established.

2. The Effect on the Fed of Chloroform Administered to the Feeder.-In no experiment did we allow this condition of cross circulation to continue uninfluenced for any length of time, so that we cannot say how long the brain would continue to be supplied with blood adequate to maintain respiration in the fed animal. In all cases as soon as the immediate effects of establishment of the cross circulation had passed off and the blood pressures of both animals were fairly con: stant chloroform was administered either to the feeder or to the fed. As chloroform given to the feejer is carried to the brain of the fed the experiment corresponds to the injection of the drug into the carotis or vertebral and so shall be considered before the administration to the fed, which, in so far as the drug has free access to the heart but is excluded from the brain, corresponds to the injection into the jugular.

In the experiment on March 19th (Fig. 7) when the pres:sures in both dogs were constant, that of the feeder being $100 \mathrm{~mm}$. and that of the fed $160 \mathrm{~mm}$. (Fig 7, Tracing $d$ ), the tube in the trachea of the feeder was connected with a chloroform bottle and in a few seconds the blood pressure in this animal began to fall in the usual way and complete absence of the conjunctival reflex was produced in $1 \mathrm{~min}$. 20 secs. The Bblood pressure of the fed animal, whose brain was receiving the same chloroform-carrying blood as that of the feeder, began after 20 secs. not to fall, but on the contrary to rise, and rose :slowly and steadily as that of the feeder fell. (Fig. 7, Tracings $e, t, g, h)$. When the chloroform had been administered for 1 min. 30 secs. and the pressure of the feeder reduced from $100 \mathrm{~mm}$. to $62 \mathrm{~mm}$. that of the fed had risen from $160 \mathrm{~mm}$. to $195 \mathrm{~mm}$., and then remained high, and when the chloroform was removed 33 secs. later, was still $195 \mathrm{~mm}$. (Fig. 7, Tracing $k$ ). The pressure of the feeder was then $60 \mathrm{~mm}$

As the feeder recovered from the chloroform its pressure of course rose, and in 1 min. 30 secs. was $88 \mathrm{~mm}$., while that of the fed fell to $186 \mathrm{~mm}$., which is still higher than it was before the chloroform was given. (Fig. 7, Tracing $n$ ). An ex:amination of the tracing shows that the rise of pressure of the fed was rather a quick one and then that it remained high. The vasomotor centre was stimulated by the chloroform and the excitation persisted and only very gradually passed off when the chloroform was removed.

Again, in another experiment, with a pressure of $68 \mathrm{~mm}$. in the feeder and $164 \mathrm{~mm}$. in the fed, chloroform was applied on a cloth to the nostrils of the feeder, and in 1 min. :30 secs., its pressure fell to $40 \mathrm{~mm}$., while that of the fed rose slightly to $170 \mathrm{~mm}$.; and again, later in the same experiments with a pressure of the feeder of $78 \mathrm{~mm}$., chloroform inhaled directly through a tube in the trachea caused, in fifty seconds, a fall of pressure to $46 \mathrm{~mm}$., while the pressure of the fed rose from $210 \mathrm{~mm}$. to $213 \mathrm{~mm}$. The same effect is seen in the experiment on February 18th (Fig. 6, Tracing $l, m, n$ ), when chloroform was given to the feeder till its respiration stopped and its blood pressure was reduced from $50 \mathrm{~mm}$. to $20 \mathrm{~mm}$.; the pressure in the fed at the same time rose from $162 \mathrm{~mm}$. to $180 \mathrm{~mm}$., and remained high, and was $178 \mathrm{~mm}$. when the respiration of the feeder stopped, four minutes after the chloroform was put on.

That chloroform-carrying blood passes to the brain of the fed is moreover indicated by the abolition of the conjunctival reflex. This was clearly shown in the last experiment referred to. Immediately before chloroform was given to the feeder, the eye of the fed gave the conjunctival reflex; but 1 min.
35 secs. later the reflex was less pronounced, and $1 \mathrm{~min}$. 36 secs. later still had quite disappeared.

These experiments conclusively show that chloroform taken up by the blood in the lungs in the ordinary way, and carried to the brain only, leads to a rise, and not to a fall of blood pressure. This rise can only be due to a direct or indirect action on the vasomotor centre. It cannot be due to increased intracranial pressure which might be caused by more blood coming from the feeder, because it takes place at a time when the blood pressure of that animal is tending to fall. Again, it cannot be considered as merely dependent on a diminished supply of blood to the brain, a relative anæmia, due to the fall of the blood pressure of the feeder, because the rise of pressure of the fed is usually established before the fall in the feeder takes place. Again, the latter is, except late in the administration of the chloroform, only small in extent, while from observations we have made on the effect of ligature of the brain arteries successively, it appears that a large diminution of the blood supply of the brain needs to be made to lead to a marked and lasting rise of pressure.

The rise of pressure observed in these experiments must then be due, largely at any rate, to a specific action of the chloroform.

Tracings of the respiration were not taken in these experiments, so that the effects produced on the respiration of the fed when chloroform was given to the feeder, can only be inferred from the respiratory undulations on the blood pressure tracing, and from such direct observations of the animal as were made at the time.

The few of these from which any inference can be drawn only show that the respiration of the fed usually becomes slower one or two minutes after chloroform is given to the feeder. Thus in one experiment with two dogs, when the respiration of the fed was 14 per minute, the administration of chloroform to the feeder led in one minute to a reduction of rate to 11 per minute; and later on, in the same experiment, led in one minute to a reduction of rate from 16 per minute to 12 per minute. Again, in the experiment with two dogs on February 18th, the rate of respiration was reduced in one minute from 29 per minute to 20 per minute. In one experiment, however-namely, that on March 19th, a quickening of respiration was in the same time produced, namely, from 15 per minute to 18 per minute.

3. The Effect on the Fed of Chloroform Administered to the Fed.- On the other hand, when chloroform is inhaled by the fed animal, and is carried to the heart and all other organs except the brain, a marked fall of blood pressure is always produced. In the experiment on February 18th (Fig. 6), where the blood pressure of the fed dog one minute after the cross circulation was established was $160 \mathrm{~mm}$. (Fig. 6, Tracing $b$ ), the tube in its trachea was connected to the chloroform bottle. After the lapse of half a minute the pressure began to fall at first slowly, and during the next minute and a.half was reduced to $136 \mathrm{~mm}$. (Fig. 6, Tracings $c, d, e$ ), it was then falling rapidly, and in eleven seconds more-that is two minutes eleven seconds after the chloroform was put on, the tracheal tube was removed from the chloroform bottle, the blood pressure being $120 \mathrm{~mm}$. It however continued to fall for twenty seconds more to $101 \mathrm{~mm}$. (Fig. 6, Tracing $f$ ), and then began to rise, and in less than a minute and a-half had regained its original height of $162 \mathrm{~mm}$. (Fig. 6, Tracings $g, h$ $k)$. The chloroform was prevented by the ligature of the brain arteries from reaching the brain; and that it did not do so is shown by the fact that the conjunctival reflex was not abolished, which it undoubtedly would have been in an intact animal supplying its own brain with blood had so extensive a fall of pressure occurred in consequence of the administration of chloroform. A gain in the experiment on March 19th, five and a-half minutes after the cross circulation was established, when the blood pressure of the fed animal was $186 \mathrm{~mm}$. (Fig. 8, Tracing a), its trachea was connected to the chloroform bottle, and in one minute the pressure had fallen to $176 \mathrm{~mm}$., in two minutes to $150 \mathrm{~mm}$., and in three minutes to $138 \mathrm{~mm}$. (Fig. 8, Tracings $b, c, d, e, f . g$.) The chloroform, however, was not removed till four minutes later; the pressure was then $132 \mathrm{~mm}$. On the withdrawal of the chloroform the pressure began to recover, and in 43 seconds was $140 \mathrm{~mm}$. (Fig. 8, Tracing $\mathrm{m}$ ), and in one minute more had reached $152 \mathrm{~mm}$. (Fig. 8, Tracing $n$ ). In the 


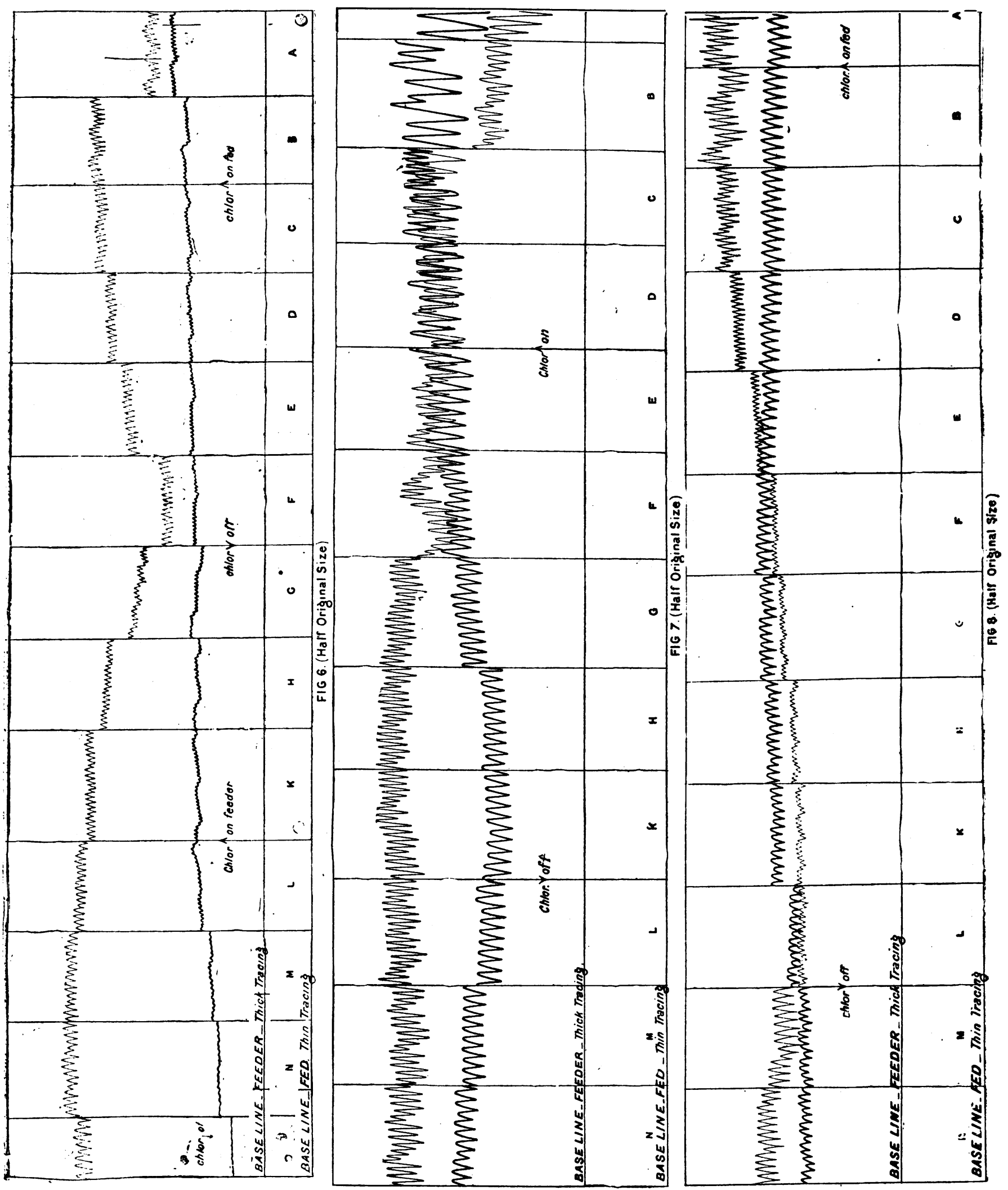




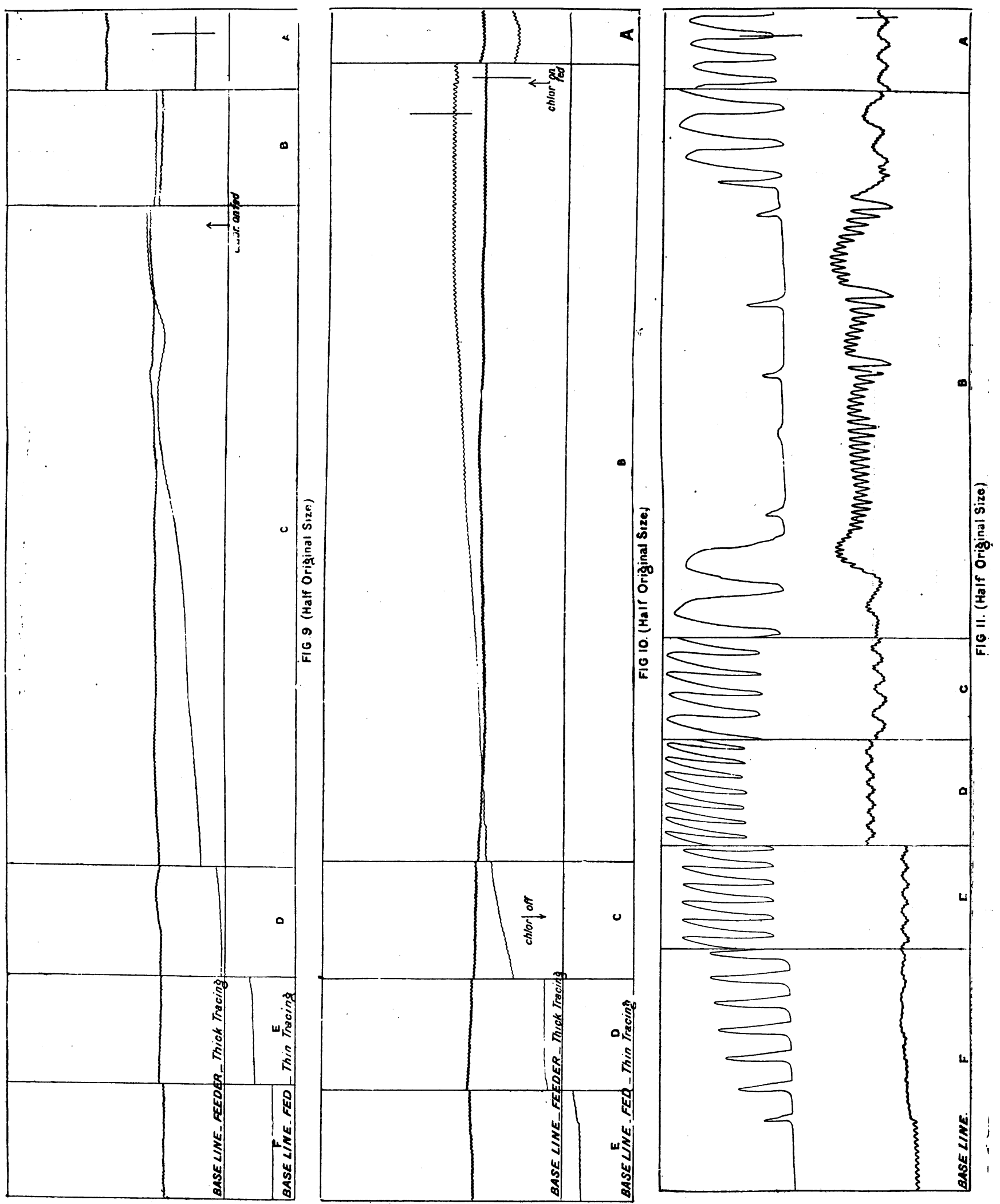


rabbit the fall of pressure was usually more rapid, and the contractions of the heart were, as far as could be judged from the blood-pressure tracing, extremely weakened so as to be quite imperceptible. This is well seen in the experiment on February 23rd (Fig. 9), when chloroform given to the fed animal when its blood pressure was $105 \mathrm{~mm}$. led to a rapid fall in one minute to $66 \mathrm{~mm}$.,

Fig. 6.-February 18th, 1891. Cross Circulation. Dogs. Peptone Injected.

Feeder.-Left carotid connected to both carotids of fed ; left jugular to right jugular of fed.

Fed.-Left subclavian proximal to vertebral tied; right ascending cervical tied; both carotids connected to left carotid of feeder; right jugular to left jugular of feeder; left external jugular tied; left vagus cut.

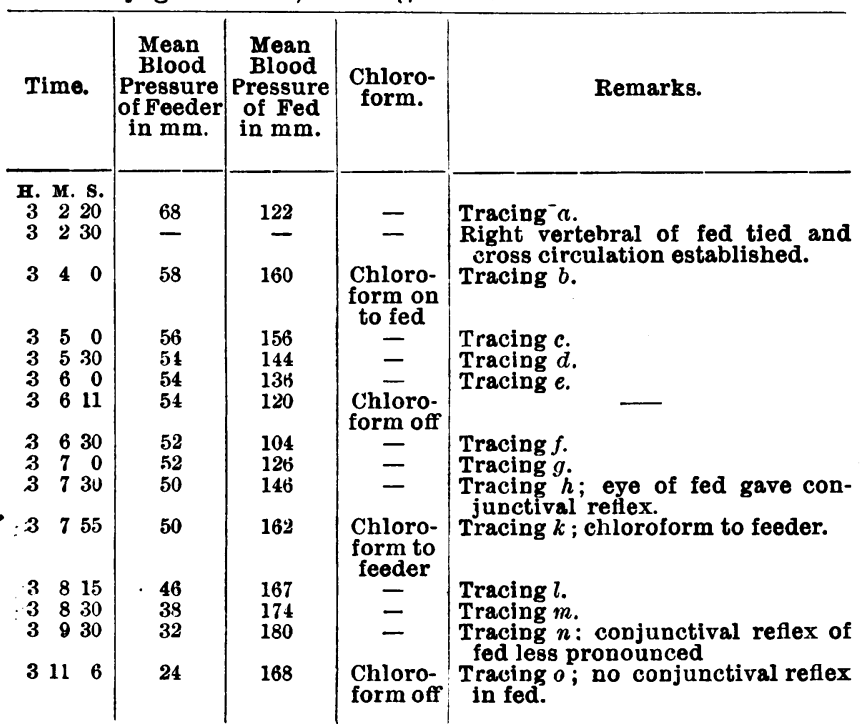

Fra. 7.-March 19th, 1891. Cross Circulation; Dogs; Chloroform to Feeder. (Leech Extract.)

Feeder.-Left carotid connected to both carotids of fed. Left jugular connected to right jugular of fed.

Fed.-Right vertebral, right and left ascending cervical ligatured. Both carotids connected to left carotid of feeder. Left jugular ligatured. Right jugular connected to left of feeder.

\begin{tabular}{|c|c|c|c|c|c|}
\hline Time. & 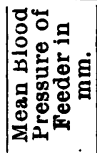 & 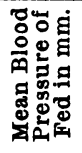 & $\begin{array}{l}\text { Chloroform } \\
\text { to Feeder. }\end{array}$ & 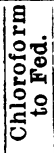 & Remarks. \\
\hline 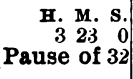 & 100 & 110 & Z & $\overline{-}$ & Tracing $a$. \\
\hline $\begin{array}{lll}4 & 9 & 0\end{array}$ & 112 & 128 & - & - & $\begin{array}{l}\text { Tracing } b \text {. At } 4 \mathrm{~h} \text {. } 9 \text { m. } 30 \text { s. } \\
\text { connections between caro- } \\
\text { tids opened. Connections } \\
\text { between jugulars opened. } \\
\text { At } 4 \text { h. } 10 \text { m. } 50 \text { s. left verte- } \\
\text { bral of fed clamped, and so } \\
\text { isolation of brain circula- } \\
\text { tion and cross circulation } \\
\text { fully established. }\end{array}$ \\
\hline $\begin{array}{rrr}4 & 11 & 0 \\
4 & 12 & 0 \\
4 & 12 & 27\end{array}$ & $\begin{array}{l}100 \\
100 \\
-\end{array}$ & $\begin{array}{l}168 \\
160 \\
-\end{array}$ & $\underset{\substack{\text { Chloroform } \\
\text { on }}}{\overline{-}}$ & $\bar{z}$ & Tracing $c$. \\
\hline $\begin{array}{lll}4 & 12 & 30 \\
4 & 13 & 0 \\
4 & 13 & 30 \\
4 & 14 & 0 \\
4 & 14 & 30\end{array}$ & $\begin{array}{l}99 \\
94 \\
82 \\
62 \\
60\end{array}$ & $\begin{array}{l}366 \\
173 \\
188 \\
197 \\
193\end{array}$ & $\begin{array}{c}\overline{-} \\
\bar{Z} \\
\substack{\text { Chloroform } \\
\text { off }}\end{array}$ & $\begin{array}{l}\overline{-} \\
\overline{-}\end{array}$ & $\begin{array}{l}\text { Tracing } e . \\
\text { Tracing } f . \\
\text { Tracing } g . \\
\text { Tracing } h . \\
\text { Tracing } k .\end{array}$ \\
\hline $\begin{array}{rrr}4 & 15 & 0 \\
4 & 15 & 30 \\
4 & 16 & 0\end{array}$ & $\begin{array}{l}66 \\
74 \\
83\end{array}$ & $\begin{array}{l}190 \\
188 \\
186\end{array}$ & = & - & $\begin{array}{l}\text { Tracing } l_{0} \\
\text { Tracing } m . \\
\text { Tracing } n .\end{array}$ \\
\hline
\end{tabular}

FIG. 8.-March 19th, 1891. Cross Circulation; Dogs; Chloroform to Fed. (Continuation of the Experiment illustrated by Fig. \%.)

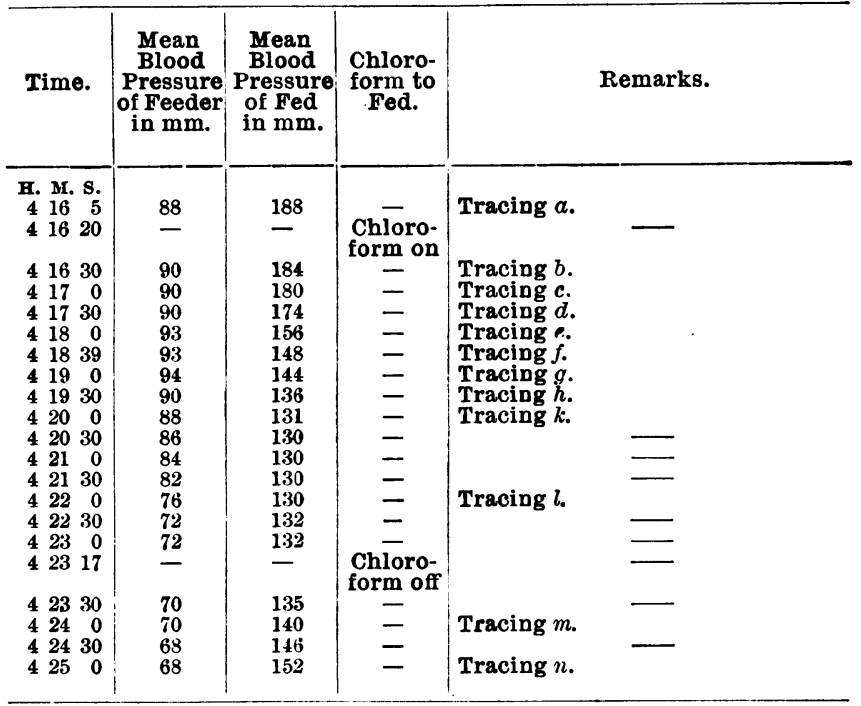

Fig. 9.-February 23rd, 1891. Cross Circulation. Two Rabbits. (Leech Extract.)

Feeder.-Carotids connected to carotids of fed respectively. Left subclavian to right subclavian of fed. Left jugular to right jugular of fed.

Fed.-Carotids to carotids of feeder respectively. Right subclavian tied proximal to vertebral, and with all branches except vertebral ligatured, connected to left subclavian of feeder. Right jugular to left jugular of feeder.

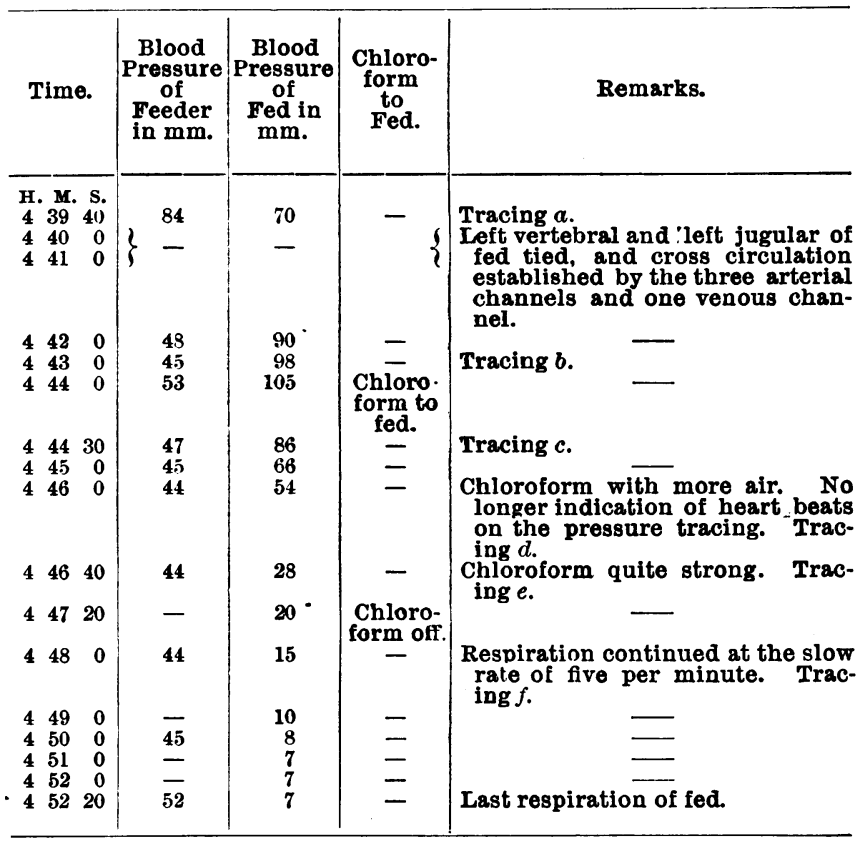

in two minutes to $54 \mathrm{~mm}$, and in three minutes to $24 \mathrm{~mm}$; and twenty seconds later, when the chloroform was taken off, the pressure was only $20 \mathrm{~mm}$. (Fig. 9, Tracings $c, d, e$ ). No indication of the beat of the heart could be seen on the tracing before this stage, and there was no recovery of the blood pressure after the chloroform was removed, for it continued to fall still further, and in five minutes more was 
$7 \mathrm{~mm}$. Except for a pause in the respiration for about twenty seconds immediately after the chloroform was removed, the animal continued to breathe for the whole of this time, its brain being of course supplied with blood from the feeder. After the natural respiration had ceased, artificial respiration was put on for four minutes, but there was no recovery in the blood pressure, and a needle placed in the heart showed no sign of movement.

Again, in the experiment on February 20th, when the blood pressure was $131 \mathrm{~mm}$., the trachea of the fed animal was connected with the chloroform bottle, and in one minute the pressure had fallen to $107 \mathrm{~mm}$. (Fig. 10, Tracing $b$ ), and when the chloroform was taken off thirty seconds later was $84 \mathrm{~mm}$.; the pressure was then falling rapidly (Fig. 10,

Fig. 10.-February 20th, 1891. Cross Circulation between Two Rabbits. (Leech Extract Injected into Jugular Vein of Fed at 1 p.m.; of Feeder at 1.20 p.m.)

In fed rabbit right carotis, right vertebral, and left subclavian were ligatured, so that animal only had left carotis open to supply the brain region.

In feeder the carotids on both sides were prepared, but not tied.

\begin{tabular}{|c|c|c|c|c|}
\hline Time. & 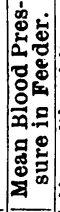 & 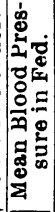 & 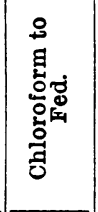 & Remarks. \\
\hline $\begin{array}{rr}\text { I. } & \text { M. S. S. } \\
\end{array}$ & 60 & 87 & - & $\begin{array}{l}\text { Leech extract injected into feeder. Pressure in } \\
\text { both animals remained very constant, with } \\
\text { heart beats showing plainly on both tracings. } \\
\text { Leech extract injected into fed at } 2 \mathrm{~h} \text {. } 7 \mathrm{~m} \text {. } 30 \mathrm{~s} \text {. } \\
\text { This injection produced no effect on the } \\
\text { tracing. }\end{array}$ \\
\hline 280 & 62 & 87 & - & $\begin{array}{l}\text { Tracing } a \text {. } \\
\text { The cross circulation was now begun to be } \\
\text { established, but by mistake the connection } \\
\text { between the left carotis of the fed and the } \\
\text { right carotis of the feeder was begun first ; in } \\
\text { consequence, immediately upon the ligature } \\
\text { of the left carotis of the fed the brain of the } \\
\text { latter was for the moment deprived of all } \\
\text { blood, with the result of causing Kussmaul. } \\
\text { Tenner convulsions and a threatening of ces- } \\
\text { sation of respiration. Artificial respiration } \\
\text { was at once put on, and the cross circulation } \\
\text { as quickly as possible established by connect. } \\
\text { ing together the right carotis of the fed with } \\
\text { the left cartis of the feeder and the right } \\
\text { jugular vein of the fed to the left jugular of } \\
\text { the feeder when when the cross circulation was } \\
\text { well established the artificial respiration was } \\
\text { removed, and the fed animal was found to be } \\
\text { breathing spontaneously without any sign of } \\
\text { convulsions. The effects produced by this ac- } \\
\text { cidental ligature of the only remaining brain } \\
\text { artery of the fed is very instructive as it } \\
\text { demonstrates in the clearest way the efficiency } \\
\text { of the cross circulation ; without cross cir- } \\
\text { culation ligature of the four brain arteries } \\
\text { produces convulsions and quickly cessation } \\
\text { of respiration ; with cross circulation ligature } \\
\text { of the four brain arteries causes no convul- } \\
\text { sions, no threatening of cessation of respira- } \\
\text { tion. }\end{array}$ \\
\hline $\begin{array}{l}23330 \\
233430\end{array}$ & $\overline{60}$ & $1 \overline{131}$ & $\begin{array}{c}\text { chilo- } \\
\text { roform } \\
\text { to fed }\end{array}$ & $\begin{array}{l}\text { Artificial respiration off. } \\
\text { The pressure on fed had been constant for half } \\
\text { a minute before the chloroform was given, and } \\
\text { heart beats were very visible on the tracing. }\end{array}$ \\
\hline 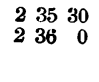 & $\begin{array}{l}58 \\
60\end{array}$ & $\begin{array}{r}107 \\
84\end{array}$ & $\begin{array}{c}\text { Chlo- } \\
\text { roform }\end{array}$ & $\begin{array}{l}\text { Tracing } b \text {. Heart beats difficult to see in tracing } \\
\text { Tracing } c \text {. Head, pressure falling very rapidly. }\end{array}$ \\
\hline $\begin{array}{lll}2 & 36 & 15 \\
2 & 36 & 30\end{array}$ & $\begin{array}{l}61 \\
62\end{array}$ & $\begin{array}{l}62 \\
36\end{array}$ & & $\begin{array}{l}\text { Tracing } d . \\
\text { Tracing } e \text {. Heart beats quite imperceptible in } \\
\text { tracing of fed. }\end{array}$ \\
\hline 23730 & 62 & 34 & - & $\begin{array}{l}\text { Respirations of fed, } 14 \text { per minute. } \\
\text { The respirations of the fed animal became } \\
\text { shallower and shallower, and finally ceased at } \\
\text { 3.40, that is, four minutes after the end of the } \\
\text { chloroform administration. Before the re- } \\
\text { spirations had ceased the slowened heart beats } \\
\text { of the fed animal reappeared on the tracing } \\
\text { for a time and caused the mean blood pressure } \\
\text { to rise to } 56 \mathrm{~mm} \text {. at } 3.30 \text {. }\end{array}$ \\
\hline
\end{tabular}

Tracing $c$ ), and thirty seconds later the pressure had sunk to $36 \mathrm{~mm}$., and there were no longer indications on the tracing of heart beats. The respiration continued for three minutes and a-half after the indication of heart beat was lost. The heart was not permanently arrested, as, after an apparent cessation of beat for about two minutes, it commenced to beat again, and continued to beat slowly for about three minutes, and then gradually stopped.

These cross-circulation experiments confirm absolutely the previous experiments in which chloroform was injected directly into the circulation. In both cases the blood containing chloroform excites the vasomotor centre and raises the blood pressure when it reaches the medulla oblongata, while it depresses the heart's action and lowers the blood pressure when it reaches the heart.

It is, then, clearly proved that the primary fall of blood pressure seen during chloroform administration is not due to paralysis of the vasomotor centre. We must, then, look beyond the central nervous system for an explanation of this fall-that is, to a direct paralysing action of the drug upon the vascular system-a direct action, therefore, upon the heart and blood vessels.

[To be continued.]

\section{VENESECTION IN CERTAIN HAMORRHAGIC FORMS OF PHTHISIS.}

By WILliaM R. HUGGARD, M.A., M.D., M.R.C.P.Lond., Davos-Platz, Switzerland.

THE value of venesection in suitable cases is now beginning to be recognised. Most of the writers dealing with the subject recently have named pulmonary tubercle as a contraindication. For example, Dr. Samuel West, in his valuable remarks on venesection, ${ }^{1}$ though stating ably the conditions in which bleeding is called for, says that in hæmoptysis it must ever remain a matter of theory rather than of practice.

I record two cases which go very far towards proving that in certain instances of pulmonary tubercle venesection can be performed with great advantage. As a rule in hæmoptysis, the loss of blood, when amounting to 8 or 10 ounces, or even more, does not seem to have a harmful effect on the general condition of the patient. On the contrary, a distinct improvement is often noticed to follow the loss of blood. But an aggravation of the disease usually occurs when a portion of the lung becomes blocked by the blood; and many cases have come under my notice in which I believe that the damage to the lung by the effused blood has been mainly responsible for the extension or for the more rapid advance of the disease. This thought had been frequently in my mind when a case exemplifying the point in question came under my observation. The clinical history is briefly as follows:CASE I-A young man of good physique but not very good family history, had a copious hæmorrhage in April and again in November, 1890. In the beginning of 1891 he came to Davos. The physical signs were slight fiattening over the upper portion of the right lung, and considerable dulness shading off towards the nipple. Respiration under the clavicle was broncho-vesicular, but with a slightly amphoric character over a small area. No rales were present, and the expectoration was small in quantity, but contained elastic fibres and a moderate number of tubercle bacill. There was a slight alternoon rise of temperature, and some night sweating; the pulse was quick. In the course of a few months all evidence of actions hardly perceptible ; and the breathing was less bronchial. The temperature regained its normal lovel. thing expectoration almost disappeared, and for a time was free from baclili, which however reappeared again later on. The patient in the mean time had become very plethoric. One evening a ter rusnlog roud his room (hn hase of a mouse) he Jelt something "give way" in his chest between the right nipple and sternum, and aiter a few moments a moutheules of medium size were to be heard dicated by the patient molst sticky rales of medium slze were to be heard over an ar the pabout a couple of square lnches. The tension and rate of the pulse were nearly as usual, the tension being high and the rate about 96. A hypodermo moctic kept in bed. Two mornings later all slgas of peared : there was no cough and no rales. In the evening I was sent for blood, having previously had the same sensation of something " having given way." When I looked at the plethoric face of the patient and fel the high tension of the pulse, I was convinced that the only rational treatment was to get rid of the excessive quantity of blood, but by some readily consented to be bled. He then told me that on a former occasion 